\title{
Transient stability enhancement of DC-connected DFIG and its converter system using fault protective device
}

\author{
Shaomin YAN ${ }^{1,2}$, Aimin ZHANG ${ }^{3}$, Hang ZHANG ${ }^{1}$, Jianhua WANG ${ }^{1}$, \\ Bin $\mathbf{C A I}^{2}$
}

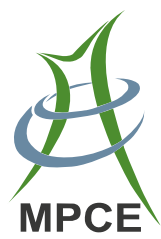

\begin{abstract}
Transient stability of doubly-fed induction generators (DFIGs) is a major concern in both AC and DC grids, and DFIGs must stay connected for a time during grid faults according to the power grid requirements. For this purpose, this work proposes an overcurrent and overvoltage protective device (OCV-PD) to ensure that DCbased DFIG system can stay connected and operate well during the faults. Compared with a series dynamic braking resistor (SDBR), two aspects are improved. First, a twolevel control strategy and DC inductor circuit are used to ensure that the OCV-PD can limit the current impulse to protect DFIG system during an overcurrent fault. Second, the OCV-PD can protect system from overvoltage fault which a SDBR cannot do. Simulation results verify its
\end{abstract}

CrossCheck date: 8 October 2017

Received: 17 April 2017/Accepted: 8 October 2017/Published online: 20 November 2017

(C) The Author(s) 2017. This article is an open access publication

$\triangle$ Aimin ZHANG

zhangam@mail.xjtu.edu.cn

Shaomin YAN

qfnuyan@163.com

Hang ZHANG

zhangh@mail.xjtu.edu.cn

Jianhua WANG

jhwang@mail.xjtu.edu.cn

Bin CAI

bincai1027@126.com

1 School of Electrical Engineering, Xi' an Jiaotong University, Xi'an, China

2 School of Engineering, Qufu Normal University, Rizhao, China

3 School of Electronic and Information Engineering, Xi' an Jiaotong University, Xi'an, China validity and feasibility, finding that for overcurrent protection the OCV-PD outperforms a SDBR with an average decreased index of $3.29 \%$, and for overvoltage protection it achieves an average index of $1.02 \%$.

Keywords Transient stability, Doubly-fed induction generator (DFIG), Overcurrent and overvoltage protective device (OCV-PD), DC grid, Series dynamic braking resistor (SDBR)

\section{Introduction}

In recent years, the variable-speed wind turbine with doubly-fed induction generator (DFIG) has gained popularity as a smart renewable energy source, due to its operational flexibility and enhanced features [1, 2]. However, a DFIG system inevitably faces the problems of overvoltage and overcurrent in extreme situations [3]. During a short-circuit fault, a very high current flows through both stator and rotor windings, and the terminal voltage of the DFIG becomes very low [4]. A DFIG system is traditionally disconnected from AC grid when there is a short-circuit fault [5]. In the event of an open-circuit fault, the current flows are very low and the terminal voltage becomes very high, which threatens its operation and eventually burns the DFIG and its converters. However with more and more wind power integrating into the grid, it is necessary for DFIGs to stay connected during faults for a time according to the power grid requirements $[6,7]$. DFIGs should therefore have good transient stability and fault ride-through capability [8]. The converter system can maintain its stability under some fault conditions $[9,10]$, however, its capacity alone is insufficient to ensure its 
stability in severe cases. Therefore, additional devices are required.

Different kinds of solutions have been proposed to overcome the issue of AC grid instabilities affecting connected wind farms. A static synchronous compensator can be applied to the wind farm $\mathrm{AC}$ bus to compensate the reactive power and stabilize AC voltage [11-13]. Circuit configurations including a fault current limiter (FCL) and energy storage systems such as flywheel energy storage (FES) and superconducting magnetic energy storage (SMES) can also improve the transient stability of DFIGs [14-16], but their high installation cost offsets their good performance [17]. A bridge-type fault current limiter (BFCL) has been proposed to enhance the transient stability of DFIGs, which is a promising application in an AC grid [18-21], but it only suits specific situations. A SDBR has a simple structure, which is applied in both AC and DC grids to enhance the transient stability and fault ridethrough capability of generators [22-24], but it cannot overcome both overcurrent and overvoltage issues and current impulse usually occurs.

With the increasing use of DC transmission, DC-based DFIG systems have been widely applied in a DC grid [25-27]. A diode-based stator converter interfaces a DFIG with a DC grid, which simplifies its converter structure, reduces its cost and improves its efficiency [26, 28], however this diode-based converter has no protective ability and exposes the DFIG to DC grid faults. An IGBTbased stator converter is a promising DC-based converter which connects a DFIG to a DC grid directly with lower levels of current harmonics and higher power quality [27, 29-31], but its protective ability is insufficient during serious DC grid faults.

Few solutions are proposed in the literature to solve transient stability issues of DC-connected DFIGs. SMES with a FCL function can improve the low voltage ridethrough capability and smooth the power fluctuations of a DFIG in a DC grid [32], but it only applies to traditional DFIG systems and its installation cost is high.

Thus it is important to protect DFIGs with DC-based converter systems from the full range of DC grid faults.

This paper focuses on a DC overcurrent and overvoltage protective device (OCV-PD) to enhance the transient stability of DC-based DFIG systems. Compared with a SDBR, the proposed OCV-PD could make DC-based DFIGs less influenced by overcurrent faults in the all power situations with less impulse currents; Moreover, it has overvoltage protective ability that SDBR does not possess. In this paper, a DC-based DFIG system is presented in Section 2; the design and control scheme of the OCV-PD are elaborated in Section 3; and simulation studies are carried out to verify the effectiveness of OCV-PD in Section 4, where the results show that OCV-PD is effective and feasible.

\section{DC-based DFIG system}

The DC-based converter system adopted in this paper is shown in Fig. 1, and has been widely applied in DC-interfaced wind farms [27, 29-31]. It consists of a rotor side converter (RSC) and a stator side converter (SSC). The RSC is an IGBT-based converter that couples the rotor to the DC bus. The SSC interfaces the stator and the DC bus, which consists of an IGBT-based converter and a $L C$ inductor. $L C$ and $\mathrm{d} u / \mathrm{d} t$ filter inductors are added to the stator and rotor sides to prevent sharp changes in voltage caused by converters and to smooth the stator and rotor currents.

\subsection{DC-based converter system model}

RSC and SSC models are described as [29, 33, 34]:

$\left\{\begin{array}{l}u_{r d}=R_{r} i_{r d}+\sigma L_{r} \frac{\mathrm{d}}{\mathrm{d} t} i_{r d}-s \omega_{1} \sigma L_{r} i_{r q}+s \frac{L_{m}}{L_{s}} u_{s} \\ u_{r q}=R_{r} i_{r q}+\sigma L_{r} \frac{\mathrm{d}}{\mathrm{d} t} i_{r q}+s \omega_{1} \sigma L_{r} i_{r d}\end{array}\right.$

$\left\{\begin{array}{l}L \frac{\mathrm{d} i_{L d}}{\mathrm{~d} t}=u_{s d}-R_{L} i_{L d}+\omega_{1} L i_{L q}-v_{s d} \\ L \frac{\mathrm{d} i_{L q}}{\mathrm{~d} t}=u_{s q}-R_{L} i_{L q}-\omega_{1} L i_{L d}-v_{s q}\end{array}\right.$

$\left\{\begin{array}{l}C \frac{\mathrm{d} u_{s d}}{\mathrm{~d} t}=i_{L d}-i_{s d}+\omega_{1} C u_{s q} \\ C \frac{\mathrm{d} u_{s q}}{\mathrm{~d} t}=i_{L q}-i_{s q}-\omega_{1} C u_{s d}\end{array}\right.$

where $u_{s d}, u_{s q}, i_{s d}, i_{s q}$ are the $d q$ components of stator voltage and current; $u_{r d}, u_{r q}, i_{r d}, i_{r q}$ are the $d q$ components of rotor voltage and current; $\omega_{1}$ is the synchronous angular frequency; $L_{s}, L_{r}, L_{m}$ are the stator, rotor and mutual inductance; $R_{r}$ is the rotor resistance; $u_{s}$ is the stator voltage; $v_{s d}, v_{s q}, i_{L d}, i_{L q}$ are the $d q$ components of stator converter voltage and current; $C$ and $L$ are the capacitance and inductance of $L C$ filter; $\sigma$ is $1-L_{m}^{2} /\left(L_{s} L_{r}\right)$.

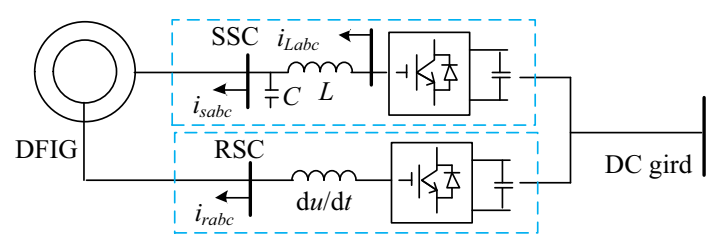

Fig. 1 DFIG with its DC-based converter system in DC grid 


\subsection{Control scheme for DC-based DFIG system}

The control equations can be derived from (1)-(3) as:

$\left\{\begin{array}{l}u_{r d}=\left(k_{r p}+\frac{k_{r i}}{s}\right)\left(i_{r d}^{*}-i_{r d}\right)-s \omega_{1} \sigma L_{r} i_{r q}+s \frac{L_{m}}{L_{s}} u_{s} \\ u_{r q}=\left(k_{r p}+\frac{k_{r i}}{s}\right)\left(i_{r q}^{*}-i_{r q}\right)+s \omega_{1} \sigma L_{r} i_{r d}\end{array}\right.$

$\left\{\begin{array}{l}i_{L d}=\left(k_{u p}+\frac{k_{u i}}{s}\right)\left(u_{s d}^{*}-u_{s d}\right)-\omega_{1} C u_{s q}+i_{s d} \\ i_{L q}=\left(k_{u p}+\frac{k_{u i}}{s}\right)\left(u_{s q}^{*}-u_{s q}\right)+\omega_{1} C u_{s d}+i_{s q}\end{array}\right.$

$\left\{\begin{array}{l}v_{d}=\left(k_{s p}+\frac{k_{s i}}{s}\right)\left(i_{L d}^{*}-i_{L d}\right)-\omega_{1} L i_{s q}+u_{s d} \\ v_{q}=\left(k_{s p}+\frac{k_{s i}}{s}\right)\left(i_{L q}^{*}-i_{L q}\right)+\omega_{1} L i_{s d}+u_{s q}\end{array}\right.$
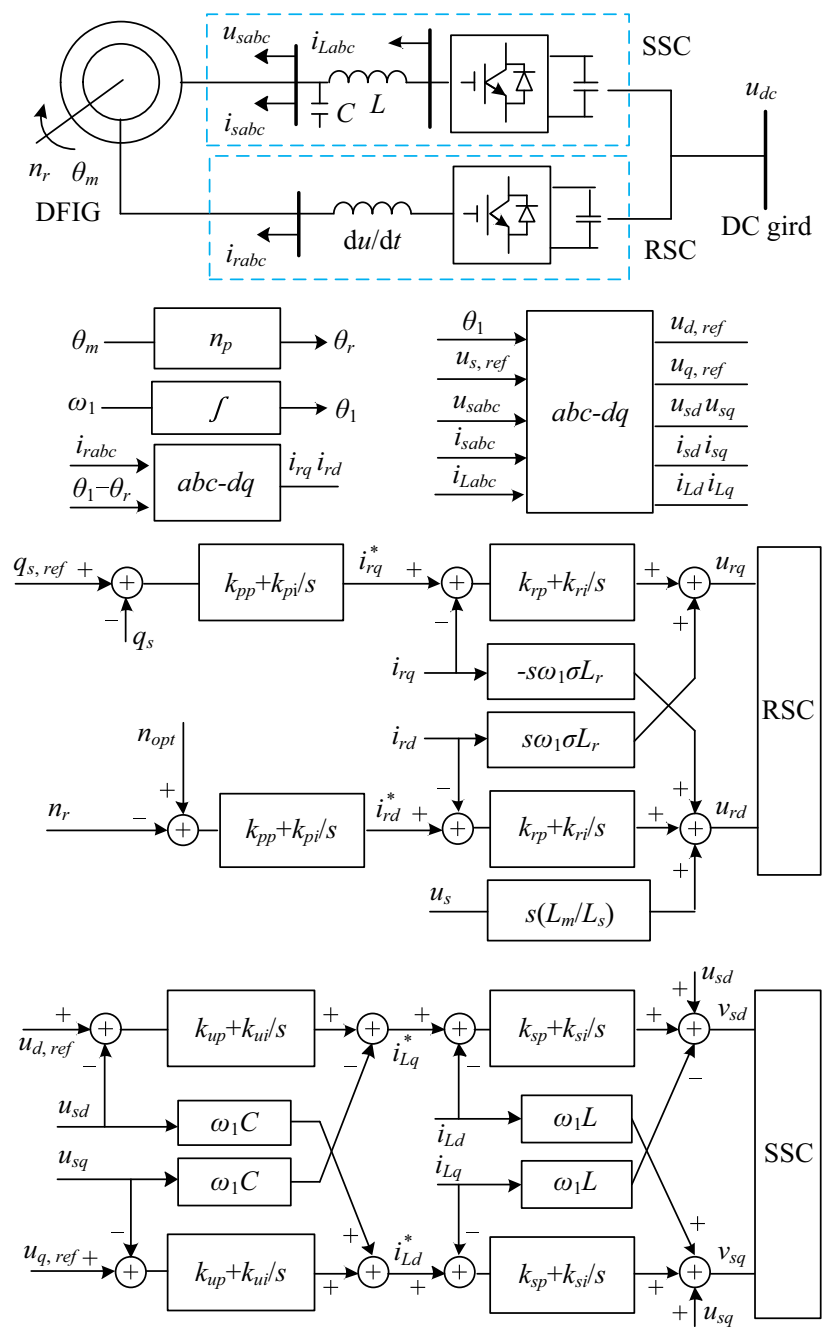

Fig. 2 Whole control strategy of SSC and RSC where $n_{r}, n_{\text {opt }}, \theta_{m}$ are the rotor speed, optimal speed, and rotor angle. From (4) to (6), the whole control scheme of converter system can be obtained, as shown in Fig. 2.

The RSC undertakes the stator power control task to track the wind power curve, and its control strategy consists of a power regulator and a current regulator. The SSC stabilizes stator voltage and converts AC power to DC power; its control strategy consists of a voltage regulator and a current regulator. The voltage and angle references come from an ideal AC voltage source. The parameters of an example DFIG system and controllers are provided in Tables 1 and 2 respectively.

\section{Overcurrent and overvoltage protective device}

\subsection{OCV-PD configuration}

The proposed OCV-PD consists of a serial inductor circuit (SIC), a shunt resistance (SR), a snubber circuit (SC), IGBTs $\left(k_{m}\right.$ and $\left.k_{s}\right)$, and a diode $\left(D_{c o n}\right)$ as shown in Fig. 3. The overcurrent protective circuit (OCPC) includes the SIC, SC, SR, $k_{m}$ and $D_{c o n}$. The overvoltage protective circuit (OVPC) consists of the SIC, SR and $k_{s} . V_{b u s G}$ and $V_{\text {busF }}$ are the voltages of the DC grid and the wind farm respectively. The SIC includes a reactor $\left(L_{s i c}\right)$, a resistance $\left(R_{s i c}\right)$, and a diode $\left(D_{\text {sic }}\right)$, which smooths the DC current and limits the burst current. $D_{\text {sic }}$ provides the path to discharge the stored reactor energy. $R_{s i c}$ is the internal resistance of the reactor. The SC consists of a reactor $\left(L_{s c}\right)$ and a diode $\left(D_{s c}\right)$, which protects $k_{m}$ from a current impulse when the IGBT is turned on instantaneously. The SR consists of multi-branch resistances with DC switches $\left(k_{1}, k_{2}, \ldots, k_{n}\right)$ placed in series, which generate different equivalent resistance to adapt to variable power. $D_{c o n}$ connects the SR to the DC bus and prevents the DC bus current from experiencing an overcurrent fault. It also separates the SR from the DC bus and protects the DC bus from overvoltage faults.

\subsection{OCV-PD operation}

During normal operation, $k_{m}$ stays on and $k_{s}$ stays off, therefore current flows through the SIC, SC and $k_{m}$. The

Table 1 Parameters for 1.5 MW DFIG system

\begin{tabular}{llll}
\hline Characteristic & Value & Characteristic & Value \\
\hline Stator voltage & $0.575 \mathrm{kV}$ & Stator resistance & 0.023 p.u. \\
Stator reactance & 0.18 p.u. & Rotor resistance & 0.016 p.u. \\
Rotor reactance & 0.16 p.u. & Magnetic reactance & 2.9 p.u. \\
\hline
\end{tabular}


Table 2 Parameters of PI controllers

\begin{tabular}{llll}
\hline Characteristic & Value & Characteristic & Value \\
\hline$k_{p p}$ & 4 & $k_{u p}$ & 3 \\
$k_{p i}$ & 0.1 & $k_{u i}$ & 0.15 \\
$k_{r p}$ & 0.0496 & $k_{s p}$ & 0.1 \\
$k_{r i}$ & 0.0128 & $k_{s i}$ & 0.01 \\
\hline
\end{tabular}

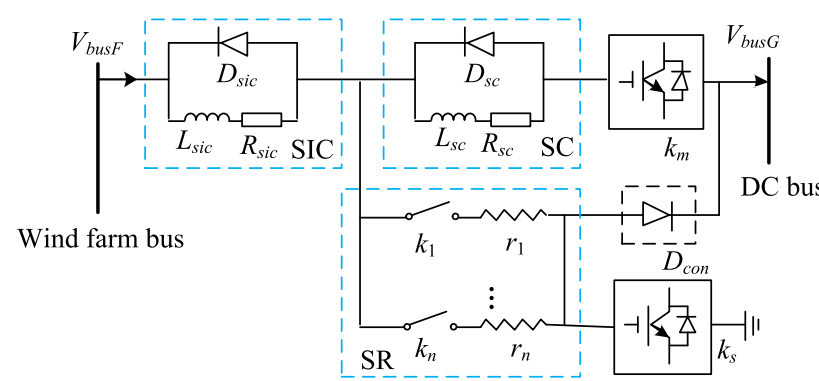

Fig. 3 OCV-PD circuit

OCPC has no impact on DC current, and the voltage drop caused by the SIC and the SC is quite negligible. The SR is chosen to be large enough so that the leakage current through it may be ignored.

During the short-circuit and overcurrent fault, the DC current initially increases very sharply, but the SIC and SC limit its rate of increase. Thus, $k_{m}$ is protected from high values of $\mathrm{d} i / \mathrm{d} t$ and operates safely. $k_{m}$ is controlled when the DC current increases beyond a preset value $\left(i_{t h}\right)$ that is defined as 1.3 times the normal DC current. Note that, the lower $i_{t h}$ is, the greater is the risk of misjudging a fault response, which may result in power fluctuation and unnecessary current harmonics. Meanwhile the higher $i_{t h}$ is, the greater is the delay in response by the OCPC. During the fault response the DC current flows through the SR, which limits the fault current and consumes excess energy. $k_{m}$ is turned on when the short-circuit fault is cleared and $V_{\text {busG }}$ recovers to $90 \%$ of its nominal value $\left(V_{\text {ref }}\right)$.

During an open-circuit and overvoltage fault, $V_{\text {busF }}$ increases sharply or has an initial fluctuation. $k_{m}$ stays open and $k_{s}$ starts to work when $V_{\text {busF }}$ is beyond a preset value $\left(V_{d c, \text { max }}\right)$ that is defined as 1.3 times the reference DC voltage $\left(V_{d c, r e f}\right)$. During the fault response the DC current flows through the SR to consume excess energy. $k_{s}$ is turned off and $k_{m}$ stays on when the overvoltage fault is cleared and $V_{b u s F}$ recovers to $105 \%$ of $V_{d c, r e f}$.

\subsection{OCV-PD design consideration}

In order to protect DC-based DFIGs from the full range of power system faults, the two main factors to consider are choosing an appropriate shunt resistance $\left(R_{s c}\right)$ and DC reactor $\left(L_{\text {sic }}\right)$.

The OCV-PD needs to consume excess power equal to the amount that the faulted DC bus carries in normal operation. Two-level control is adopted to control the IGBTs $\left(k_{m}\right.$ and $\left.k_{s}\right)$ and multi-branch resistances to get an accurate equivalent resistance with variable wind output power. The total number of branches is:

$N=\frac{P_{\max }}{P_{b r}}$

where $P_{\max }$ and $P_{b r}$ are the maximum wind farm output power and the branch resistance power respectively. A larger number of branches gives a more accurate equivalent resistance. Here two branches are used to show the operating principle. During the normal and faulted periods, the number of branches applied is determined by:

$n \leq \frac{P_{w}}{P_{b r}}$

where $n$ and $P_{w}$ are the number of branches and the wind farm output power respectively. The DC switches $\left(k_{1}, k_{2}\right)$ are controlled once every $10 \mathrm{~s}$.

The OCV-PD offers more impedance than a SDBR to smooth burst currents and reduce power fluctuations, but a big reactance may cause control delays and DC voltage fluctuations. The value of the impedance is mainly determined by this requirement [32]:

$\operatorname{Min} \int_{t_{0}}^{t_{s}}(|\Delta p(t)|+|\Delta u(t)|) \mathrm{d} t$

where $\Delta p(t)$ and $\Delta u(t)$ are the power and voltage deviations of the wind farm; $t_{0}$ and $t_{s}$ are the initial and final fault times. Taking the factors mentioned above together, a value of $1.02 \mathrm{mH}$ for $L_{\text {sic }}$ is found to give good performance for this system. Considering that a time constant $\left(L_{s c} / R_{s c}\right)$ of $3.33 \mathrm{~s}$ is good enough for smoothing abrupt changes of current [20], $R_{s c}$ and $L_{s c}$ are chosen to be

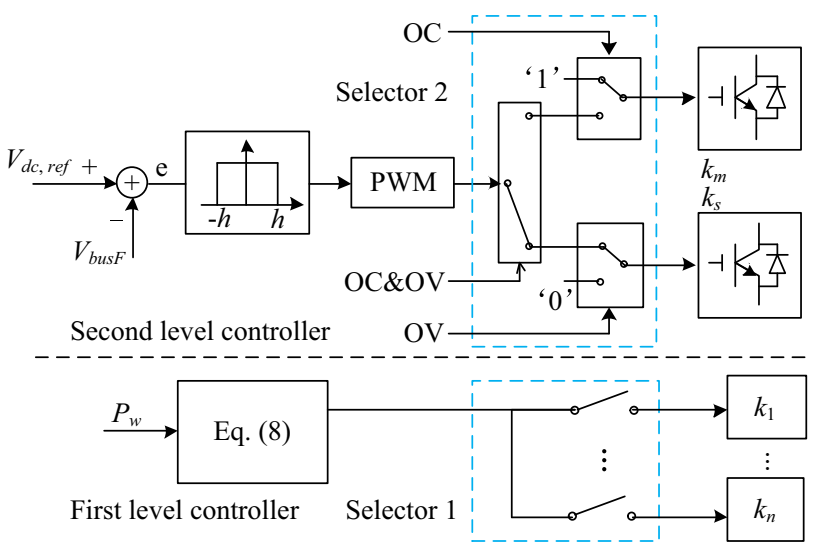

Fig. 4 Control strategy of OCV-PD 
$0.003 \mathrm{~m} \Omega$ and $0.01 \mathrm{mH}$ for a practical solution, and $R_{\text {sic }}$ is chosen to be $0.33 \mathrm{~m} \Omega$ in the same way.

\subsection{OCV-PD control strategy}

The two-level control strategy shown in Fig. 4 is used to ensure that the OCV-PD can adapt to variable output power. The first level controller selects the applied quantity of DC switches $\left(k_{1}, k_{2}, \ldots, k_{n}\right)$ once every $10 \mathrm{~s}$ according to the output power of wind farm to approximate the required equivalent resistance. The second level controller determines $k_{m}$ and $k_{s}$ to get an accurate equivalent resistance in overcurrent and overvoltage fault situations. It consists of a hysteresis control unit, a pulse width modulation (PWM) generator, two selectors, and two IGBTs $\left(k_{m}\right.$ and $\left.k_{s}\right)$. In order to alleviate DC voltage fluctuations, $V_{\text {bus }}$ is used as the feedback reference. A hysteresis controller is used to produce an appropriate signal for the PWM generator with a hysteresis bandwidth of $1 \mathrm{~V}$. The PWM signals ' 0 ' and ' 1 ' are sent to IGBTs $\left(k_{s}\right.$ and $k_{m}$ ) via selector 2 . The overcurrent (OC) and overvoltage (OV) flags are mentioned above.

\subsection{SDBR design considerations}

The performance of the OCV-PD can be compared with that of a SDBR to demonstrate its effectiveness. A SDBR consists of an IGBT $\left(k_{m}\right)$ and a resistor $\left(R_{s h}\right)[20,22-24]$ as shown in Fig. 5.

During normal operation, $k_{m}$ stays on. Therefore, the DC current flows through $k_{m}$ and bypasses $R_{s h}$. During an overcurrent fault, the DC current increases very sharply. $k_{m}$ is turned off and $R_{s h}$ is switched into DC transmission to consume excess power. $k_{m}$ is turned on when the overcurrent fault is cleared and the DC voltage recovers.

There is no DC inductor, so current impulses may occur. The resistor is chosen to be equal to the equivalent resistance to allow direct comparison. The working condition of SDBR is same as that of OCV-PD.

\section{Simulation and discussion}

A simulation platform has been developed to verify the effectiveness and feasibility of the OCV-PD in Fig. 6, which consists of six DFIG systems, protective devices

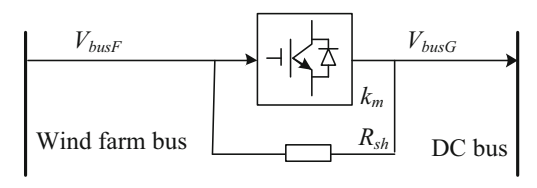

Fig. 5 SDBR circuit

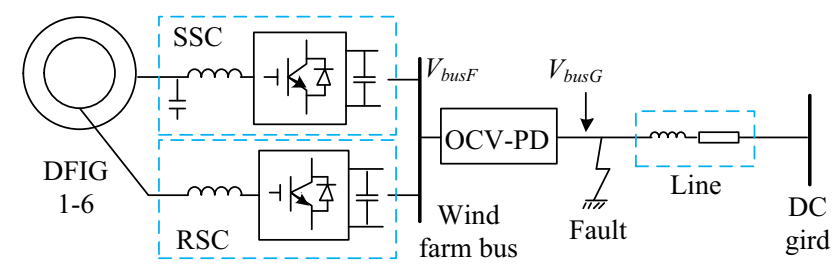

Fig. 6 Test platform description

(OCV-PD and SDBR), fault scenarios, transmission line and DC grid. Protection devices are installed on the wind farm bus. The performance of the OCV-PD and the SDBR is compared when an overcurrent fault occurs, and the system performance is analyzed to validate the overvoltage protective ability of the OCV-PD during an open-circuit fault.

\subsection{Simulation settings}

The simulated DFIG systems operate at their rated speed steadily before faults occur at $0.05 \mathrm{~s}$. Faults are cleared at $0.15 \mathrm{~s}$. Three cases are considered when an overcurrent fault occurs:

1) Case A: with no protective device.

2) Case B: with an OCV-PD.

3) Case C: with a SDBR.

Since a SDBR cannot protect the DFIG systems from an overvoltage fault, two cases are considered:

1) Case A: with no protective device.

2) Case B: with an OCV-PD.

Simulation results and analysis are carried out in the following sections. The black and dot-dash lines are the curves for case A. The red and solid lines are the curves for case B. The blue and dotted lines are the curves for case $\mathrm{C}$.

\subsection{Transient stability analysis for short-circuit fault}

Figures 7 and 8 show the responses of an OCV-PD and a DFIG system when an overcurrent fault occurs.

In Fig. $7 \mathrm{a}, V_{\text {busG }}$ is 1.0 p.u. initially, then falls down to 0.22 p.u. during 0.05 to 0.15 s. In Fig. $7 \mathrm{~b}, V_{d c F}$ is lowest right after the fault occurs for case $\mathrm{A}$, and has a big damped oscillation with amplitude of 0.2 p.u. for case C. Meanwhile the OCV-PD keeps $V_{d c F}$ at 1.0 p.u. after a small transient regulation. When the overcurrent fault is cleared, $V_{d c F}$ recovers most quickly for case B.

In Fig. 7c, the abrupt current is limited by the DC reactor for case $\mathrm{B}$, and its current fluctuation is the 


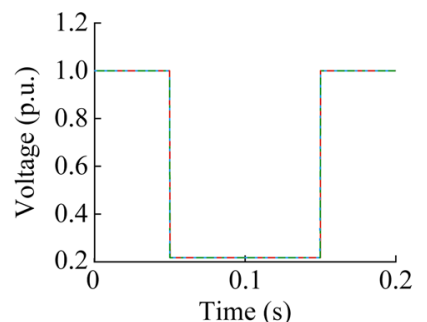

(a) Bus voltage

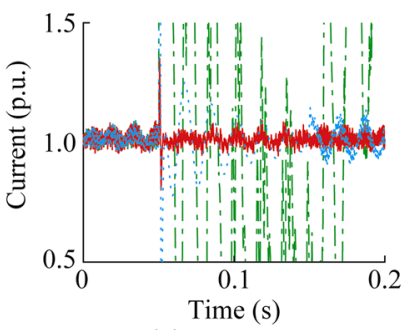

(c) DC current

(c) - Case A.

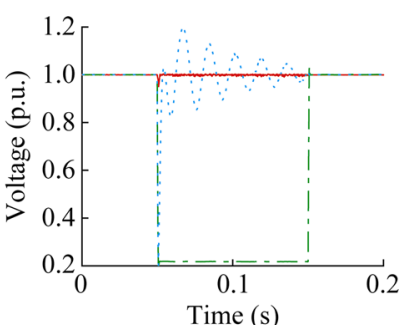

(b) Windfarm voltage

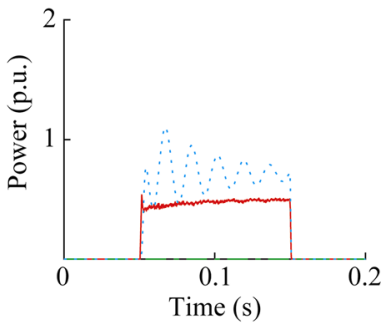

(d) Comsumed power Case C
Fig. 7 Performance of protective device during short-circuit fault

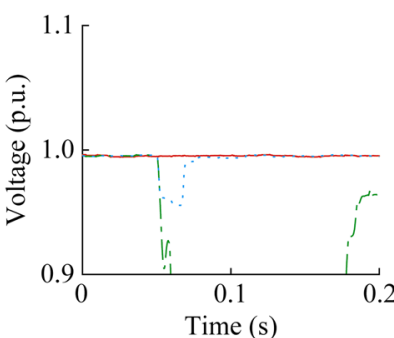

(a) Sator voltage

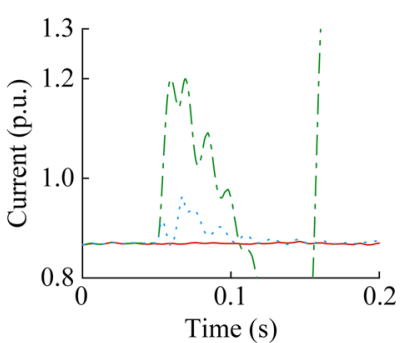

(c) Rotor current

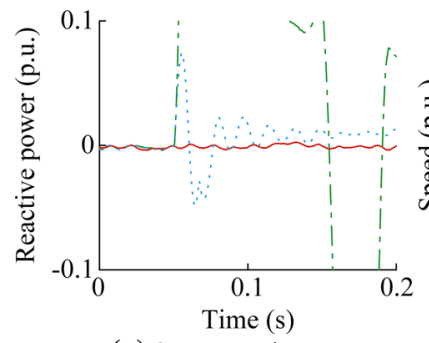

(e) Sator reactive power

-..-- Case A; $\longrightarrow$ Case B;

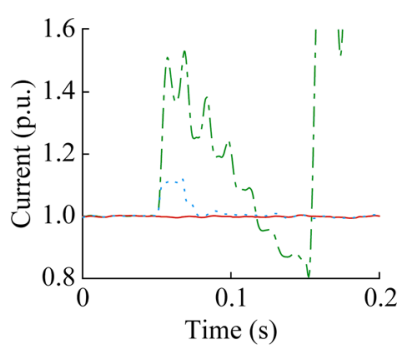

(b) Sator current

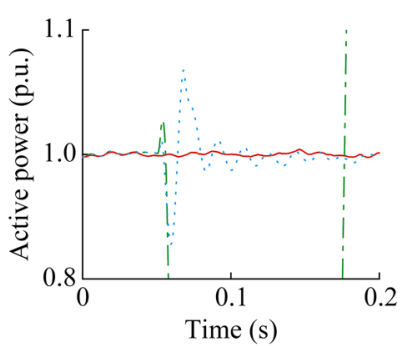

(d) Sator active power

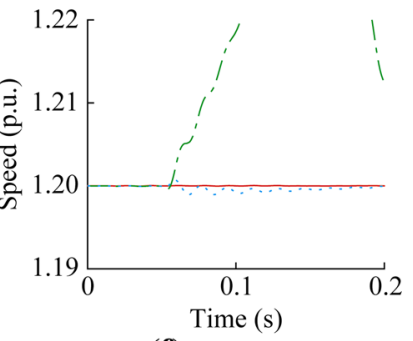

(f) Rotor speed

Case C
Fig. 8 Performance of DFIG system during short-circuit fault smallest. Power devices in the OCV-PD and DC-based converter system are safe during the overcurrent fault, however an abrupt current exists for cases $\mathrm{A}$ and $\mathrm{C}$, which may damage the power devices.

In Fig. 7d, the OCV-PD consumes more appropriate active power and gives better transient stability than the SDBR during the overcurrent fault. Power is not consumed by the SR during normal operation for cases B and C.

Considering now the DFIG, in Fig. 8a, when the DC bus voltage drops, the wind farm and stator voltages decrease instantaneously since no protective device exists for case $\mathrm{A}$, and then stator voltage is regulated by the SSC to a level that is below the normal value. For case $\mathrm{C}$, since wind farm voltage is not influenced much due to the protection of the SDBR, the stator voltage decreases from 1 to 0.95 p.u. under the regulation of the SSC, and then recovers to 1.0 p.u.. For case B, the stator voltage is not influenced and stable wind farm voltage is achieved due to the protection of the OCV-PD.

In Fig. $8 \mathrm{~b}$ and c, stator current varies with stator voltage, which would make the rotor current change similarly. The lower stator voltage causes a higher stator current. Therefore, the stator current becomes high for case A during an overcurrent fault, and the system may break down if the fault time is too long. For cases B and C, the OCV-PD limits the current's rising rate and ensures better transient stability with lower oscillation, which is more than the SDBR can achieve. The current responses of the stator and the rotor have similar waveforms.

Figure $8 \mathrm{~d}$ and e show how the active and reactive power of the DFIG respond to the system current and voltage. With the drop in voltage and increase in current, the active power decreases to a very low level for case A during the overcurrent fault, and increases to a very high level when the fault is cleared, which may harm the DFIG and its converter system; and reactive power increases to a high level due to the big system current. For case B, active and reactive power remain stable at 1 and 0 p.u. respectively for the stable system voltage and current due to the protection of the OCV-PD. For case C, the active and reactive power have oscillations with amplitudes of 0.07 p.u..

In Fig. 8f, since wind power is approximately constant during the overcurrent fault, the rotor speed increases very quickly with the decrease in active power for case $\mathrm{A}$. The rotor speed for case B is more constant than that for case C, and both are influenced slightly.

Simulation results indicate that the OCV-PD can protect the DC-based DFIG system from an overcurrent fault, and it can do so more effective than the SDBR. 


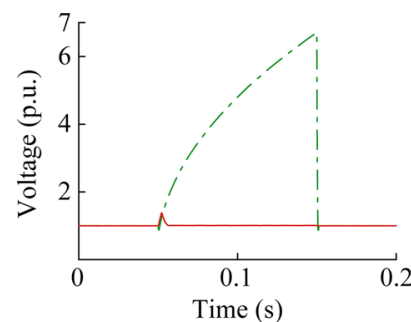

(a) Bus voltage

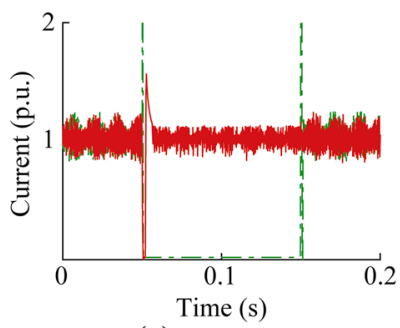

(c) DC current

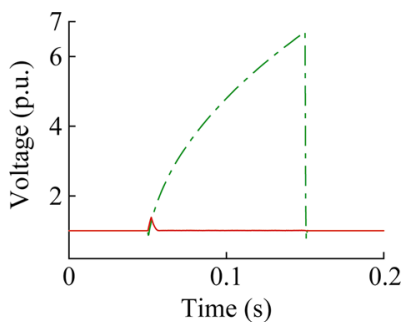

(b) Windfarm voltage

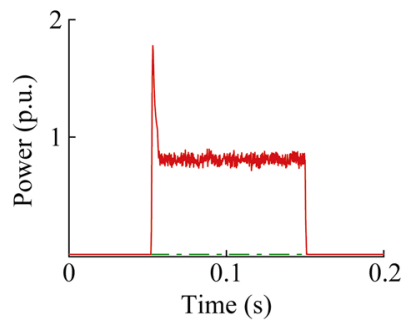

(d) Comsumed power Case B
Fig. 9 Performance of protective device during overvoltage fault

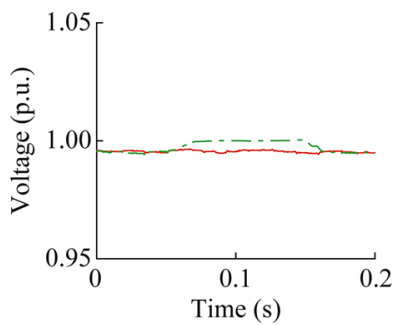

(a) Sator voltage

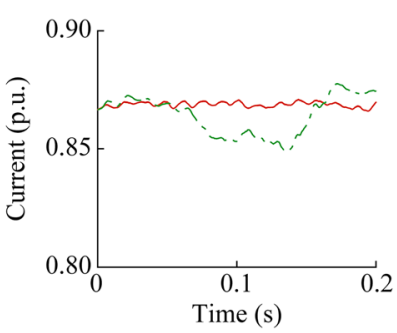

(c) Rotor current

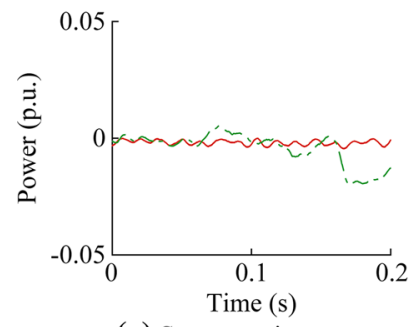

(e) Sator reactive power

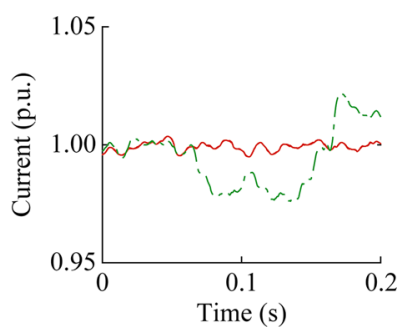

(b) Sator current

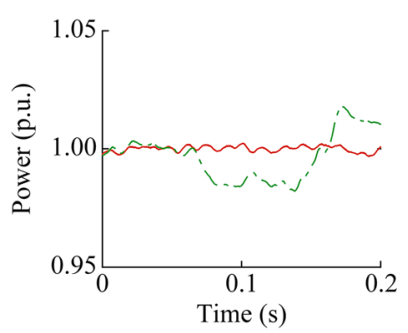

(d) Sator active power

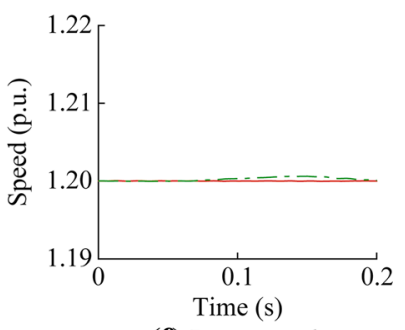

(f) Rotor speed

$$
\text { -..- Case A; — Case B }
$$

Fig. 10 Performance of DFIG system during overvoltage fault

\subsection{Transient stability analysis for overvoltage fault}

Figures 9 and 10 describe the responses of an OCV-PD and a DC-based DFIG system during an open-circuit fault that causes overvoltage.

In Fig. 9a, b, and c, $V_{\text {busF }}$ and $V_{\text {busG }}$ become high right after the overvoltage fault occurs, and the DC current decreases to zero with a sudden impulse for case A. The DC-based converter system should not be subjected to such a high voltage and current impulse, which may damage the capacitor and converter. On the other hand, the DC voltage and current remain close to their nominal values after a transient oscillation for case $\mathrm{B}$, and recover quickly with the help of the OCV-PD when the fault is cleared.

In Fig. 9d, the OCV-PD consumes excess active power during the overvoltage fault, but does not consume wind power during normal operation.

The responses of the DFIG system for cases A and B are illustrated in Fig. 10. Since the DC wind farm voltage is not influenced by the overvoltage fault due to the protection of the OCV-PD, the stator voltage, stator current, rotor current, stator active and reactive power, and rotor speed remain essentially at their normal values during the overvoltage fault. Although the DFIG system is less affected in case A during the overvoltage fault than during the overcurrent fault, overvoltage in a wind farm would damage the DC-based converter system, so an overvoltage protection device is needed.

From the results, we can see that the DFIG system operates in a stable state with the lowest voltage fluctuation and limited current impulse for case B, which indicates that the OCV-PD can protect the DC-based DFIG system from overvoltage and overcurrent faults.

\subsection{Index comparison}

In order to illustrate the relative performances in a quantitative way, eight indices are defined as:

$$
\left\{\begin{array}{l}
s p=\int_{t_{0}}^{t_{s}}|\Delta p(t)| \mathrm{d} t \\
s q=\int_{t_{0}}^{t_{s}}|\Delta q(t)| \mathrm{d} t \\
s \omega_{r}=\int_{t_{0}}^{t_{s}}\left|\Delta \omega_{r}(t)\right| \mathrm{d} t \\
s U_{d c}=\int_{t_{t}}^{t_{s}}\left|\Delta U_{d c}(t)\right| \mathrm{d} t \\
s I_{s}=\int_{t_{0}}^{t_{s}}\left|\Delta I_{s}(t)\right| \mathrm{d} t \\
s V_{s}=\int_{t_{s}}^{t_{s}}\left|\Delta V_{s}(t)\right| \mathrm{d} t \\
s I_{r}=\int_{t_{0}}^{t_{s}}\left|\Delta I_{r}(t)\right| \mathrm{d} t \\
s I_{d c}=\int_{t_{0}}^{t_{s}}\left|\Delta I_{d c}(t)\right| \mathrm{d} t
\end{array}\right.
$$

where $\Delta p(t), \Delta q(t), \Delta \omega_{r}(t), \Delta I_{r}(t), \Delta I_{s}(t), \Delta V_{s}(t), \Delta U_{d c}(t)$, $\Delta I_{d c}(t)$ are the deviations of the real and reactive power of 
Table 3 Performance indices for short-circuit faults

\begin{tabular}{lcrl}
\hline Index parameters & \multicolumn{2}{l}{ Values of indices $(\%)$} \\
\cline { 2 - 4 } & No protective device & SDBR & OCV-PD \\
\hline$s p$ & 542.24 & 7.54 & 0.96 \\
$s q$ & 194.61 & 12.57 & 1.08 \\
$s \omega_{r}$ & 1.80 & 0.03 & 0.002 \\
$s I_{s}$ & 44.08 & 1.43 & 0.16 \\
$s I_{r}$ & 31.09 & 1.19 & 0.11 \\
$s V_{s}$ & 32.95 & 0.36 & 0.03 \\
$s U_{d c}$ & 35.95 & 2.63 & 0.11 \\
$I_{d c}$ & 68.51 & 5.33 & 1.87 \\
Average index & 118.9 & 3.89 & 0.6 \\
\hline
\end{tabular}

Table 4 Performance indices for open-circuit faults

\begin{tabular}{lcl}
\hline Index parameters & \multicolumn{2}{c}{ Values of indices $(\%)$} \\
\cline { 2 - 3 } & No protective device & OCV-PD \\
\hline$s p$ & 9.93 & 1.00 \\
$s q$ & 4.66 & 0.76 \\
$s \omega_{r}$ & 0.003 & 0.001 \\
$s I_{s}$ & 1.35 & 0.18 \\
$s I_{r}$ & 0.98 & 0.11 \\
$s V_{s}$ & 0.33 & 0.04 \\
$s U_{d c}$ & 184.90 & 0.37 \\
$I_{d c}$ & 64.66 & 5.69 \\
Average index & 33.3 & 1.02 \\
\hline
\end{tabular}

the generator, the rotor speed, the rotor and stator current, the stator voltage, and the DC voltage and current, respectively. The integrals are calculated over the time range from 0.05 and $0.15 \mathrm{~s}$, and the indices are expressed as a percentage of the average value of each parameter integrated over the same period, hence they measure the percentage average normalized deviation.

Tables 3 and 4 are obtained when the simulation results in Figs. 7-10 are substituted into (10). A lower index represents a better system performance regarding transient stability. The system performance for case $\mathrm{A}$ is the worst with the average indices of $119 \%$ and $33 \%$ during overcurrent and overvoltage faults. The indices for cases B and $\mathrm{C}$ are $0.6 \%$ and $3.89 \%$ during the overcurrent fault. The index for case B is $1.02 \%$ during the overvoltage fault.

Thus the OCV-PD makes a significant improvement and outperforms the SDBR by reducing the average normalized deviation from $3.89 \%$ to $0.6 \%$; moreover, the OCV-PD can protect system from overvoltage fault with an average normalized deviation of $1.02 \%$, while the SDBR cannot provide this protection.

\subsection{Implementation feasibility}

The OCV-PD would probably be located at the substation of wind farms and use local parameters without needing additional signal detection equipment. The OCVPD incorporates power electronic devices that have made astounding advances in recent times and are readily available. Cascaded and parallel configurations could be used in situations of very large current and voltage. Thus the OCV-PD could be feasible both technically and financially.

\section{Conclusion}

Based on the simulation results and analysis, the following conclusions may be drawn.

1) The OCV-PD can effectively protect DC-based DFIG systems from overvoltage and overcurrent faults to enhance their transient stability.

2) The OCV-PD outperforms a SDBR during an overcurrent fault, reducing the average normalized deviation from $3.89 \%$ to $0.6 \%$ according to the graphical and numerical results from a simulated system.

3) The OCV-PD ensures that the DFIG can operate well during an overvoltage fault with an average normalized deviation of $1.02 \%$.

In our future research, a prototype of the OCV-PD will be manufactured and tested to verify its effectiveness.

Acknowledgements This work was supported by Natural Science Foundation of China (No. 61473170) and Key R\&D Plan Project of Shandong Province, PRC (No. 2016GSF115018).

Open Access This article is distributed under the terms of the Creative Commons Attribution 4.0 International License (http:// creativecommons.org/licenses/by/4.0/), which permits unrestricted use, distribution, and reproduction in any medium, provided you give appropriate credit to the original author(s) and the source, provide a link to the Creative Commons license, and indicate if changes were made.

\section{References}

[1] Li H, Chen Z (2008) Overview of different wind generator systems and their comparisons. IET Renew Power Gener 2(2):123-138

[2] Yannopoulos SI, Lyberatos G, Theodossiou N et al (2015) Evolution of water lifting devices (pumps) over the centuries worldwide. Water 7:5031-5060

[3] Sun T, Chen Z, Blaabjerg F (2005) Transient stability of DFIG wind turbines at an external short-circuit fault. Wind Energy 8(3):345-360 
[4] Jafari M, Naderi S, Hagh M et al (2011) Voltage sag compensation of point of common coupling (PCC) using fault current limiter. IEEE Trans Power Deliv 26(4):2638-2646

[5] Okedu KE, Muyeen S, Takahashi R et al (2012) Wind farms fault ride through using DFIG with new protection scheme. IEEE Trans Sustain Energy 3(2):242-254

[6] Tsili M, Papathanassiou S (2009) A review of grid code technical requirements for wind farms. IET Renew Power Gener 3(3):308-332

[7] Lin L, Zhao H, Lan T et al (2013) Transient stability mechanism of DFIG wind farm and grid-connected power system. In: Proceedings of IEEE PowerTech, Grenoble, France, 16-20 June 2013, 9 pp

[8] Seta PL, Schegner P (2007) New control scheme for doubly-fed induction generators to improve transient stability. In: Proceedings of IEEE Power Engineering Society General Meeting, Tampa, FL, USA, 24-28 June 2007, 10 pp

[9] Xiang D, Ran L, Tavner PJ et al (2006) Control of a doubly fed induction generator in a wind turbine during grid fault ridethrough. IEEE Trans Energy Convers 21(3):652-662

[10] Rahimi M, Parniani M (2010) Transient performance improvement of wind turbines with doubly fed induction generators using nonlinear control strategy. IEEE Trans Energy Convers 25(2):514-525

[11] Muyeen S, Takahashi R, Murata T et al (2009) Low voltage ride through capability enhancement of wind turbine generator system during network disturbance. IET Renew Power Gener 3(1):65-74

[12] Wang L, Truong D-N (2013) Stability enhancement of DFIGbased offshore wind farm fed to a multi-machine system using a STATCOM. IEEE Trans Power Syst 28(3):2882-2889

[13] Latha KS, Kumar MV (2014) STATCOM for enhancement of voltage stability of a DFIG driven wind turbine. In: Proceedings of Power and Energy Systems Conference: Towards Sustainable Energy, Bangalore, India, 13-15 March 2014, 5 pp

[14] Ali M, Wu B, Dougal RA (2010) An overview of SMES applications in power and energy systems. IEEE Trans Sustain Energy 1(1):38-47

[15] Wang L, Yu JY, Chen YT (2011) Dynamic stability improvement of an integrated offshore wind and marine-current farm using a flywheel energy-storage system. IET Renew Power Gener 5(5):387-396

[16] Wang L, Chen SS (2012) Stability improvement of a grid-connected offshore wind farm using a superconducting magnetic energy storage. In: Proceedings of Industry Applications Society Annual Meeting, Las Vegas, NV, USA, 7-11 Oct 2012, 8 pp

[17] Gong B, Xu D, Wu B (2010) Cost effective method for DFIG fault ride-through during symmetrical voltage dip. In: Proceedings of 36th Annual Conference on IEEE Industrial Electronics Society, Glendale, AZ, USA, 7-10 Nov 2010, 6 pp

[18] Salami Y, Firouzi M (2011) Dynamic performance of wind farms with bridge-type superconducting fault current limiter in distribution grid. In: Proceedings of 2nd International Conference on Electric Power and Energy Conversion Systems, Sharjah, United Arab Emirates, 15-17 Nov 2011, 6 pp

[19] Zhao Y, Krause O, Saha T et al (2013) Stability enhancement in distribution systems with DFIG-based wind turbine by use of SFCL. In: Proceedings of Australas Univ Power Eng Conf (AUPEC), Hobart, TAS, Australia, 29 Sept-3 Oct 2013, 6 pp

[20] Rashid G, Ali MH (2015) Transient stability enhancement of doubly fed induction machine-based wind generator by bridge- type gault current limiter. IEEE Trans Energy Convers 30(3):939-947

[21] Rashid G, Ali MH (2014) A modified bridge-type fault current limiter for fault ride-through capacity enhancement of fixed speed wind generator. IEEE Trans Energy Convers 29(2):527-534

[22] Causebrook A, Atkinson DJ, Jack AG (2007) Fault ride-through of large wind farms using series dynamic braking resistors. IEEE Trans Power Syst 22(3):966-975

[23] Hossain MK, Ali M (2014) Low voltage ride through capability enhancement of grid connected PV system by SDBR. In: Proceedings of IEEE T\&D Conf Expo, Chicago, IL, USA, 14-17 April 2014, 5 pp

[24] Soliman H, Wang H, Zhou D et al (2014) Sizing of the series dynamic breaking resistor in a doubly fed induction generator wind turbine. In: Proceedings of IEEE Energy Conv Cong Expo, Pittsburgh, PA, USA, 14-18 Sept 2014, 5 pp

[25] Heng N, Yi X (2014) HVDC power transmission oriented gridconnection topology and control strategy for wind farm composed of doubly fed induction generators. Power Syst Technol 38(7):1731-1738

[26] Marques G, Iacchetti MF (2014) Inner control method and frequency regulation of a DFIG connected to a DC link. IEEE Trans Energy Convers 29(2):435-444

[27] Yan S, Zhang A, Zhang H et al (2017) Optimized and coordinated model predictive control scheme for DFIGs with DCbased converter system. J Mod Power Syst Clean Energy 5(4):620-630. doi:10.1007/s40565-017-0299-7

[28] Marques G, Iacchetti MF (2014) Stator frequency regulation in a field oriented controlled DFIG connected to a DC link. IEEE Trans Ind Electron 61(11):5930-5939

[29] Yan S, Zhang A, Zhang H et al (2017) Control scheme for DFIG converter system based on DC-transmission. IET Electr Power Appl 11(8):1441-1448

[30] Yan S, Zhang A, Zhang H et al (2017) An optimum design for DC-based DFIG system by regulating gearbox ratio. IEEE Trans Energy Convers. doi:10.1109/TEC.2017.2741104

[31] Nian H, Yi X (2015) Coordinated control strategy for doubly-fed induction generator with DC connection topology. IET Renew Power Gener 9(7):747-756

[32] Ngamroo I, Karaipoom T (2014) Improving low-voltage ridethrough performance and alleviating power fluctuation of DFIG wind turbine in DC microgrid by optimal SMES with fault current limiting function. IEEE Trans Appl Supercond 24(5):1-5

[33] Cardenas R, Pena R, Alepuz S et al (2013) Overview of control systems for the operation of DFIGs in wind energy applications. IEEE Trans Ind Electron 60(7):2776-2798

[34] Cheng M, Zhu Y (2014) The state of the art of wind energy conversion systems and technologies: a review. Energy Convers Manag 88:332-347

Shaomin YAN received B.S in Mechanical and Electrical Engineering from Qilu University of Technology in 2001 and M.S in electrical and electronic engineering from Zhejiang University of Technology in 2004. From 2004 to 2012, he was a Lecturer in the Electrical Engineering School, Qufu Normal University. He is currently working towards the Ph.D. degree in Electrical Engineering School, $\mathrm{Xi}$ 'an Jiaotong University. His current research interests include wind energy conversion system and power electronics. 
Aimin ZHANG received the B.S., M.S. and Ph.D. degrees in Electrical Engineering from Xi' an Jiaotong University in 1983, in 1985 and in 2008 respectively. She is currently a Professor in the Electronic and Information Engineering School, Xi'an Jiaotong University. Her current research interests include FACTS, non-linear control theory, and power electronics.

Hang ZHANG received the B.S. and M.S. degrees in Electrical Engineering from Xi' an Jiaotong University in 1983 and in 1985 respectively. He is currently an Assistant Professor in the Electrical Engineering School, Xi'an Jiaotong University. His current research interests include HVDC transmission system and power electronics.
Jianhua WANG received the B.S., M.S. and Ph.D. degrees in Electrical Engineering from Xi'an Jiaotong University in 1979, in 1983, and in 1985 respectively. He is currently a Professor in the Electrical Engineering School, Xi'an Jiaotong University. His current research interests include intelligent apparatus technique, intelligent HV switchgear, and power electronics.

Bin CAI received Ph.D. degrees in Electrical Engineering from Xi' an Jiaotong University in 2004. He is currently a Professor in the Engineering School, Qufu Normal University. His current research interests include wind energy conversion system and power electronics. 